\title{
Формирование нанопористых пленок силицидов меди
}

\author{
(C) Э.Ю. Бучин, В.В. Наумов, С.В. Васильев \\ Ярославский филиал Физико-технологического института Российской академии наук, \\ 150007 Ярославль, Россия \\ E-mail: imi.buchin@rambler.ru
}

(Получена 8 августа 2018 г. Принята к печати 1 октября 2018 г.)

\begin{abstract}
Экспериментально показана возможность формирования нанопористых пленок силицидов меди разного фазового состава. Для этого параметры исходной структуры $a-\mathrm{Si} / \mathrm{Cu}$ и режимы ее отжига подбирали таким образом, чтобы процесс твердофазного синтеза останавливался на стадии образования разветвленного силицидного кластера. Затем пленки подвергали жидкостному травлению в смеси разбавленных неорганических кислот. При этом селективно удалялась метастабильная фаза $\mathrm{Cu}_{x} \mathrm{Si}$ с низким содержанием меди и высвобождался трехмерный силицидный кластер. Одновременно вскрывались приповерхностные пустоты Киркендалла (Kirkendall voids), присутствующие в пленках. В результате совокупности этих двух процессов формировалась нанопористая структура.
\end{abstract}

DOI: $10.21883 /$ FTP.2019.03.47297.8972

\section{1. Введение}

Силициды меди используются в микроэлектронике $[1,2]$, при производстве эффективных солнечных батарей и Li-ионных аккумуляторов, записывающих лазерных дисков [3-5], а также в качестве катализаторов в процессах формирования углеродных и $\mathrm{SnO}_{2}$-наноструктур [6,7]. Активное их исследование проводится и в настоящее время, что подтверждается значительным количеством публикаций по данной тематике.

В большинстве случаев применяют тонкие силицидные пленки. Для их получения медь осаждают на кремниевые подложки либо создают структуры, состоящие из слоев аморфного кремния и меди. Затем проводят вакуумный отжиг, при котором и происходит твердофазный синтез силицида меди. Несмотря на то что процесс состоит всего из двух основных стадий, осаждения и отжига, до сих пор в ходе исследований обнаруживаются все новые его особенности. Это обусловлено тем, что в системе кремний-медь существует более двух десятков кристаллических фаз, имеющих разный состав и разную структуру решетки. Диаграмма состояния бинарной системы [8] показывает, что некоторые фазовые области имеют очень узкие концентрационные и температурные диапазоны (рис. 1). При комнатной температуре стабильными являются следующие основные фазы: $\alpha-$ твердый раствор кремния в меди, $\gamma-\mathrm{Cu}_{5} \mathrm{Si}$ (пентамеди силицид), $\varepsilon-\mathrm{Cu}_{15} \mathrm{Si}_{4}$ и $\eta^{\prime \prime}-\mathrm{Cu}_{3} \mathrm{Si}$ (тримеди силицид). Формирование той или иной фазы зависит не только от соотношения компонентов в исходной структуре и температуры ее отжига, но также от уровня дефектности пленок, материала подслоя между пленочной структурой и подложкой [9] и даже от воздействия внешнего магнитного поля [10].

Кроме того, имеется большое различие в кинетических и термодинамических характеристиках компонентов. Медь быстро диффундирует в кремний, но ее растворимость в нем крайне мала, даже в случае аморфного кремния она составляет всего 0.5 ат\% при $200^{\circ}$ С. Кремний, напротив, хорошо растворяется в меди, его концентрация в межзеренном пространстве при той же температуре может достигать 15 ат\%, но медленно диффундирует [11]. Многообразие силицидных фаз и различие в указанных характеристиках меди и кремния являются причинами того, что результаты исследований, проведенных разными научными группами, не всегда полностью совпадают. Наряду с поиском новых практических приложений этот факт также отчасти стимулирует проведение работ по дальнейшему изучению твердофазного синтеза тонких пленок силицидов меди.

В ряде практических приложений силицидные пленки с развитой поверхностью (например, пористые) могут обеспечить большую эффективность их использования. Целью данной работы является исследование возможности формирования таких пленок как нового перспективного материала. Основной подход в реализации этой задачи заключается в следующем. Представленная фазовая диаграмма показывает наличие переходных областей: $\alpha+\gamma, \gamma+\varepsilon, \varepsilon+\eta^{\prime \prime}$. Они соответствуют такому состоянию вещества, когда внутри одной фазы зарождается и постепенно формируется другая фаза. Значит, можно подобрать условия твердофазного синтеза, которые позволят остановить процесс образования новой фазы на любой стадии: нуклеатизации, слияния зародышей или образования разветвленного кластера. Если затем отработать режим селективного травления остатков старой фазы, то можно сформировать пористую силицидную пленку.

\section{2. Методика эксперимента}

Для проведения исследований на кремниевые подложки $\mathrm{Si}(100)$ осаждали двух- и трехслойные пленочные структуры $a$ - $\mathrm{Si}-\mathrm{Cu}$ методом высокочастотного магнетронного распыления. Степень чистоты медной мишени 


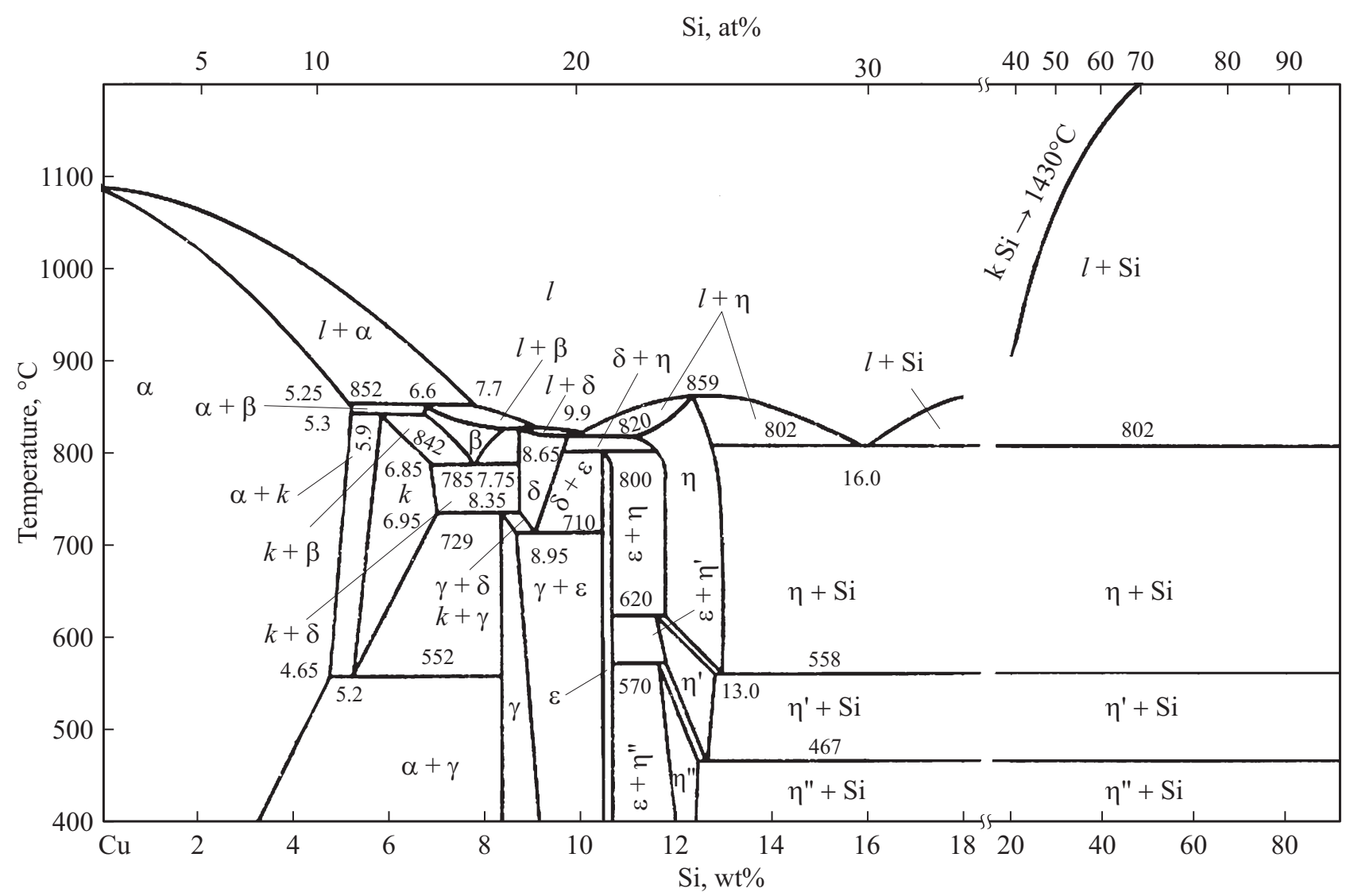

Рис. 1. Фазовая диаграмма бинарной системы кремний-медь.

составляла 99.95\%. Исходный вакуум в рабочей камере установки (SCR-651 „Теtra“ Alcatel) соответствовал остаточному давлению $5 \cdot 10^{-7}$ мбар, при напуске плазмообразующего газа (Ar) вакуум поддерживался на уровне давления $2 \cdot 10^{-4}$ мбар. Размер образцов был меньше, чем площадь зоны однородного распыления магнетрона. Этим обеспечивалась равномерность толщины пленок, осаждаемых при скорости 1 нм/с. Отжиги проводили в вакуумной камере $\left(10^{-6}\right.$ мбар) с последующей выдержкой до полного охлаждения.

Морфологию поверхности и структуру поперечных сколов образцов исследовали с помощью сканирующего электронного микроскопа (SEM) высокого разрешения „Zeiss Supra-40“. Микроскоп оснащен рентгеновской энергодисперсионной приставкой (EDX), с помощью которой проводили химический микроанализ. Рентгенографические исследования образцов как до, так и после отжига выполняли на дифрактометре ARL X'tra (Thermo Fisher Scientific) с фокусировкой по Брэггу-Брентано в режиме $(\theta-2 \theta)$-сканирования. Дифрактограммы получали с использованием $\mathrm{Cu} K_{\alpha}$-излучения (длина волны $\lambda=1.5418 \AA$ ) при ускоряющем напряжении 35 кВ и токе накала $40 \mathrm{MA}$. Идентификацию фаз осуществляли на основе картотеки Международного центра дифракционных данных ICDD PDF-2 (2009). Распределение компонентов по толщине пленки исследовали с помощью вторично-ионного масс-спектрометра с времяпролетным масс-анализатором „TOF.SIMS5“. Для распыления поверхности использовали пучок высокоэнергетичных ионов $\mathrm{Cs}^{+}$.

\section{3. Результаты экспериментов и их обсуждение}

На первом этапе исследования в качестве образцов использовали трехслойные структуры $a-\mathrm{Si}(50 \mathrm{Hм}) /$ $\mathrm{Cu}(200$ нм $) / a-\operatorname{Si}(50$ нм $)$. Известно, что при длительном отжиге пленочных структур $a-\mathrm{Si}-\mathrm{Cu}$ при температурах выше $300^{\circ} \mathrm{C}$ образуется сплошной стехиометрический силицидный слой. Чтобы избежать этого и получить пленку с кластерной структурой отжиг экспериментальных образцов проводили при температурах $100-200^{\circ} \mathrm{C}$ в течение 1-4ч. В работе [11], выполненной с применением аналитических методов высокого разрешения, было показано, что в таких структурах нижняя и верхняя границы между слоями аморфного кремния и меди различаются по своим характеристикам. На нижней межслоевой границе имеется перемешанная область толщиной $\sim 10 \mathrm{HM}$, которая образуется при осаждении меди на слой аморфного кремния. Верхняя граница является резкой и характеризуется большими градиентами концентраций. Структурное различие приводит к 
разным механизмам зарождения и роста силицидной фазы при отжиге таких структур. На нижней границе за счет наличия аморфизованной перемешанной области практически полностью отсутствует энергетический барьер для стадии зарождения кристаллитов $\mathrm{Cu}_{3} \mathrm{Si}$. Поэтому силицидный слой равномерно растет параллельно плоскости подложки. На верхней границе, являющейся резкой, для стадии образования силицидных зародышей существует высокий энергетический барьер. Образование зародышей здесь происходит следующим образом. При интенсивной диффузии кремния в межзеренное пространство меди возникают механические напряжения, релаксация которых происходит за счет канального выброса части меди в матрицу аморфного кремния с образованием преципитатов, имеющих поперечный размер $\sim 10$ нм. Затем кремний диффундирует внутрь этих преципитатов, и только тогда происходит образование силицидных зародышей, которые постепенно срастаются в стехиометрический, но не сплошной силицидный слой. Кинетика процесса носит нелинейный характер. Для того чтобы оценить влияние указанных двух механизмов образования кристаллической силицидной фазы в тонких пленках при выбранных нами режимах отжига и была использована трехслойная структура.

На рис. 2 в качестве примера представлено SEM-изображение поперечного скола такого образца, отожженного при температуре $190^{\circ} \mathrm{C}$. Хорошо видны три слоя, причем средний отличается по своей морфологии. Анализ методом вторично-ионной масс-спектрометрии (ВИМС) показал, что кремний и медь равномерно распределены по всей толщине пленочной структуры, т.е. она имеет однородный элементный состав. Морфологические различия, скорее всего, обусловлены текстурой исходной медной пленки. После 4-часового отжига верхний и нижний слои имеют равную толщину, т. е. оба они росли в среднем с одинаковой скоростью $\sim 20 \mathrm{Hм} \cdot ч^{-1}$, несмотря на различие в механизмах образования силицидной фазы.

В обоих слоях и особенно вблизи их границ хорошо различимы сферические пустоты Киркендалла

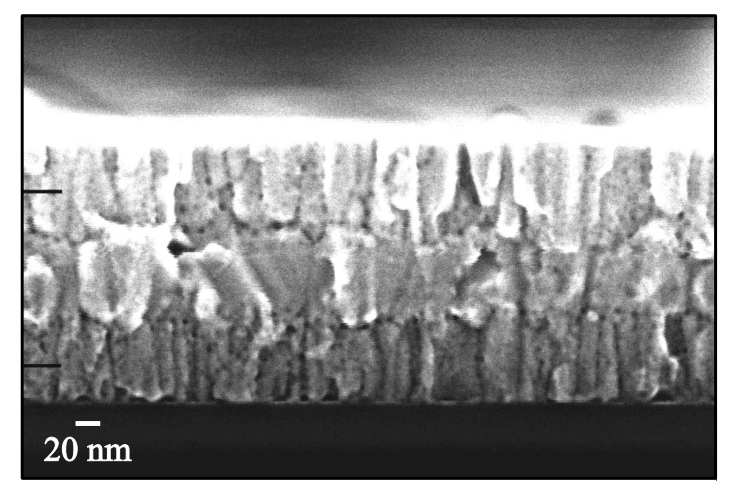

Рис. 2. SEM-изображение поперечного сечения образца, отожженного при $190^{\circ} \mathrm{C}$ (штрихами отмечено положение исходных межслоевых границ).

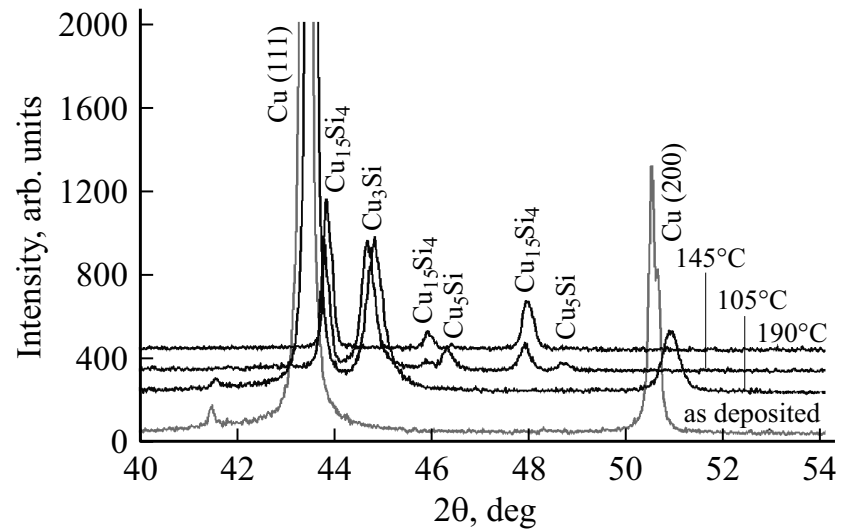

Рис. 3. Дифрактограммы экспериментальных образцов до и после отжигов.

(Kirkendall voids) диаметром $\sim(8-10)$ нм. В рассматриваемом масштабе их присутствие полностью нивелирует разницу в структуре и плотности силицидных слоев. Образование этих пустот (полостей) обусловлено большим различием в коэффициентах взаимной диффузии меди и кремния и связано с эффектом поглощения вакансий [12], концентрация которых в аморфном кремнии достигала 20 ат\%.

Был проведен ренгеноструктурный анализ трехслойных образцов, основные его результаты представлены на рис. 3. Сразу после осаждения пленок в них регистрировались только рефлексы, соответствующие поликристаллической меди. Медный слой действительно имел текстуру, что следует из соотношения интенсивностей пиков $\mathrm{Cu}(111) / \mathrm{Cu}(200)>2$. В ходе отжига в течение 4 ч при температурах $<100^{\circ} \mathrm{C}$ образовывался только твердый раствор кремния в меди. В диапазоне температур от 100 до $200^{\circ} \mathrm{C}$ формировались силицидные фазы. Так, при температуре отжига $105^{\circ} \mathrm{C}$ на дифрактограмме образца наряду с пиками, соответствующими твердому раствору, уже появляется рефлекс фазы $\mathrm{Cu}_{3} \mathrm{Si}$, т.е. в матрице твердого раствора начинается ее зарождение и развитие. Пик тримеди силицида имеет относительно большую полную ширины на полувысоте (FWHM), что соответствует фазе, представляющей собой массив произвольно ориентированных кристаллитов. При температуре $145^{\circ} \mathrm{C}$ уже $\mathrm{Cu}_{3} \mathrm{Si}$ является матрицей, в которой начинает формироваться фаза $\mathrm{Cu}_{5} \mathrm{Si}$. При $190^{\circ} \mathrm{C}$ внутри пентамеди силицида происходит формирование фазы $\mathrm{Cu}_{15} \mathrm{Si}_{4}$. Эта последовательность преобразований $\mathrm{Cu}_{3} \mathrm{Si} \rightarrow \mathrm{Cu}_{5} \mathrm{Si} \rightarrow \mathrm{Cu}_{15} \mathrm{Si}_{4}$ соответствует порядку увеличения теплоты образования этих веществ и в целом соответствует опубликованным ранее данным [13]. Однако имеет место несоответствие фазовой диаграмме, согласно которой в твердом растворе кремния в меди первым должен образовываться пентамеди силицид (область $\alpha+\gamma$ на рис. 1). Возможно, это объясняется тем, что диаграмма состояния не учитывает влияние поверхности в тонких пленках, а также поведение системы $\mathrm{Si}-\mathrm{Cu}$ при 


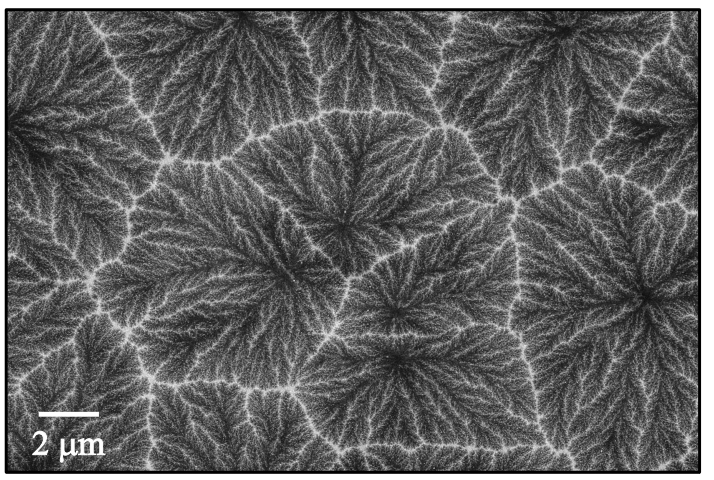

Рис. 4. SEM-изображение зернистой структуры силицидной пленки после жидкостного травления (вид сверху).

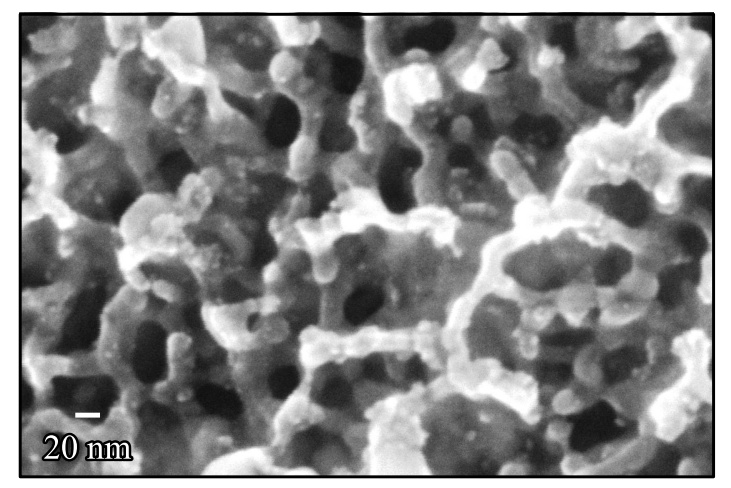

Рис. 5. SEM-изображение поверхности нанопористой силицидной пленки.

температурах ниже $200^{\circ} \mathrm{C}$. С увеличением соотношения толщин слоев до $a-\mathrm{Si} / \mathrm{Cu}>1$ при выбранной продолжительности отжига во всем указанном диапазоне температур образовывалась только мелкоблочная фаза $\mathrm{Cu}_{3} \mathrm{Si}$.

Таким образом, в ходе исследования была показана возможность формирования тонких пленок силицидов меди разного фазового состава с кластерной структурой, независимо от порядка укладки слоев.

На втором этапе работы отожженные образцы подвергали жидкостному травлению в растворах разного состава. При этом использовали двухслойные структуры $a-\mathrm{Si} / \mathrm{Cu}$ с подслоем титана, который наносили с целью исключения взаимодействия меди с монокристаллической кремниевой подложкой. При осаждении аморфного кремния на медь после отжига поверхность силицидного слоя не имеет текстуры, что облегчает задачу его селективного травления.

Наиболее интересные результаты были получены при использовании смеси разбавленных неорганических кислот, $\mathrm{H}_{2} \mathrm{SO}_{4}(5 \%)+\mathrm{HF}(3 \%)$, взятых в объемном соотношении 1:1. Оптимальное время травления образцов зависело от толщины слоев аморфного кремния и меди. Например, для структуры $a-\operatorname{Si}(100 \mathrm{HM}) /$ $\mathrm{Cu}(100 \mathrm{Hм}) / \mathrm{Ti} / c-\mathrm{Si}$ оно составляло 5 мин. На рис. 4 представлено SEM-изображение поверхности такого образца. Здесь хорошо видна необычная структура зерен силицидной пленки. После жидкостного травления все зерно представляет собой разветвленный трехмерный кластер перколяционного типа. Его строение отражает процесс гетерогенного проникновения меди в матрицу предшествующей силицидной фазы.

Дифрактограммы образцов до и после травления полностью идентичны, т.е. кристаллическая фаза остается без изменения. Следовательно, в ходе жидкостного травления селективно удаляется только метастабильная рентгеноаморфная фаза $\mathrm{Cu}_{x} \mathrm{Si}$ с низким содержанием меди, в результате чего и проявляется силицидный кластер, толщина ветвей которого находится в нанометровом диапазоне. Для того чтобы оценить их структуру и размер обратимся к рис. 5. На этом фрагменте толщина ветвей кластера составляет в среднем $20 \mathrm{Hм}$, а расстояние между ними $\sim 50$ нм. Одновременно с удалением метастабильной фазы происходит вскрытие и небольшое растравливание приповерхностных пустот Киркендалла. В совокупности этих двух процессов и формируется нанопористая силицидная пленка. Напомним, что ее фазовым составом можно управлять.

\section{4. Заключение}

Силициды меди считаются материалами, перспективными для целого ряда технических применений, поэтому они и привлекают к себе внимание исследователей. Во многих случаях используют тонкие силицидные пленки. В данной работе с применением методов сканирующей электронной микроскопии, рентгеновской дифрактометрии и вторично-ионной масс-спектрометрии показана возможность формирования нанопористых силицидных пленок. При этом, изменяя толщину слоев в исходной структуре $a-\mathrm{Si} / \mathrm{Cu}$, режимы ее низкотемпературного отжига и условия последующего селективного травления, можно управлять фазовым составом и структурными параметрами пористых пленок. Помимо известных физических свойств, характерных для силицидов меди, в таких пленках могут проявляться эффекты, обусловленные квантово-размерным ограничением.

Нанопористые пленки силицидов меди получены впервые. Близкий по типу материал, пористый компаунд $\mathrm{Cu}_{3} \mathrm{Si}$, заявлен в работе [14]. Однако он является объемной структурой, получаемой методом спекания при высоких температурах, и имеет гораздо меньшую удельную поверхность, поскольку поперечный размер пор составляет 10-100 мкм, а не столько же нм.

Полагаем, что нанопористые пленки силицидов меди найдут свое практическое применение, например, в химических источниках тока, в качестве катализаторов различных процессов и др. Аналогичным образом могут быть получены пористые пленки силицидов других металлов, которые в исходном состоянии обладают магнит- 
ными $\left(\mathrm{Cr}_{3} \mathrm{Si}\right)$, сверхпроводящими $\left(\mathrm{V}_{3} \mathrm{Si}\right)$, жаростойкими $\left(\mathrm{MoSi}_{2}\right)$ или полупроводниковыми $(\mathrm{ReSi})$ свойствами.

Данная работа выполнена с применением оборудования центра коллективного пользования „Диагностика микро- и наноструктур“ (Facilities Sharing Centre „Diagnostics of Micro- and Nano Structures“).

\section{Список литературы}

[1] T. Ohmi, T. Saito, T. Shibata, T. Nitta. Proc. Fifth Int. IEEE Conf. VLSI Multilevel Interconnection (N.Y., 1989) p. 135.

[2] C. Lavoie, F.M. Heurle, C. Cabral, jr. Microelectron Eng., 70,144 (2003).

[3] S.B. Lee, D.K. Choi, F. Philipp, K.S. Jeon, C.K. Kim. Appl. Phys. Lett., 88, 083117 (2006).

[4] H. Chen, Y. Xiao, L. Wang. J. Power Sources, 196 (16), 6657 (2011).

[5] B.M. Chen, R.L. Yeh. Proc. SPIE, 5380, 141 (2004).

[6] O. Parajuli, N. Kumar, D. Kipp, J. Hahm. Appl. Phys. Lett., 90, 173107 (2007).

[7] N. Kumar, O. Parajuli, J. Hahm. Appl. Phys. Lett., 91, 143114 (2007).

[8] Binary alloys phase diagrams, ed. by T.B. Massalski (Materials Park, OH: ASM International, 1992).

[9] А.В. Панин, А.Р. Шугуров, И.В. Ивонин, Е.В. Шестериков. ФТП, 44 (1), 118 (2010).

[10] Э.Ю. Бучин, В.В. Наумов, С.В. Васильев. ФТП, 51 (6), 844 (2017).

[11] M. Ibrahim, Z. Balong-Michels, P. Stender, D. Baither, G. Schmitz. Acta Materialia, 112, 315 (2016).

[12] A.D. Smigelskas, E.O. Kirkendall. Trans. AIME, 171, 130 (1947).

[13] L. Stolt, F.M. Heurle, J.M.E. Harper. Thin Sol. Films, 200, 147 (1991).

[14] H. Cai, D. Tong, Y. Wang, X. Song, B. Ding. J. Alloys Comp., 509, 1672 (2011).

Редактор Л.В. Шаронова

\section{Formation of nanoporous films of copper silicides}

E.Yu. Buchin, V.V. Naumov, S.V. Vasilyev

Yaroslavl Branch of Institute of Physics and Technology, Russian Academy of Sciences, 150007 Yaroslavl, Russia

Abstract The possibility of forming nanoporous films of copper silicides with different phase composition is shown experimentally. For this, the parameters of the initial structures $a-\mathrm{Si} / \mathrm{Cu}$ and their annealing modes were chosen so that the solid-phase synthesis process was stopped at the stage of branched silicide cluster formation. The films were then subjected to selective liquid etching in a mixture of dilute inorganic acids. At the same time, the metastable phase of $\mathrm{Cu}_{x} \mathrm{Si}$ with a low copper content was removed, and the Kirkendall voids present in the film were opened. Thus, a nanoporous structure of silicide films was formed. 